Revista Brasileira de Agricultura Irrigada v.10, no .3, p. 695 - 704, 2016

ISSN 1982-7679 (On-line)

Fortaleza, CE, INOVAGRI - http://www.inovagri.org.br

DOI: $10.7127 /$ rbai.v10n300432

Protocolo 432.16 - 04/04/2016 Aprovado em 10/06/2016

\title{
GRAU DE ENTUPIMENTO DE UM SISTEMA DE GOTEJAMENTO SUBSUPERFICIAL NA CULTURA DO PINHÃO-MANSO (Jatropha curcas L.)
}

\author{
Fernando Nobre Cunha ${ }^{1}$, Nelmício Furtado da Silva ${ }^{2}$, Marconi Batista Teixeira ${ }^{3}$, Luciana \\ Minervina de Freitas Moura ${ }^{4}$, Fernando Rodrigues Cabral Filho ${ }^{5}$ Flávio Henrique Ferreira \\ Gomes ${ }^{6}$
}

\section{RESUMO}

A utilização de sistemas de irrigação localizada tem se expandido cada vez mais, devido seu baixo consumo de água e alta taxa de uniformidade, porém um problema frequente da irrigação localizada é o entupimento dos emissores por partículas sólidas agravado em sistemas de irrigação subsuperficial. Deste modo, objetivou-se avaliar a influência do grau de entupimento em diferentes lâminas de irrigação, ao longo do tempo, sob a vazão e uniformidade de aplicação de água em um sistema de irrigação localizada subsuperficial. O procedimento para leitura individual da vazão dos gotejadores consistiu na pressurização do sistema, posicionamento de recipientes (1 litro) sob os respectivos drenos dos vasos com gotejadores enterrados com uma defasagem de 5 segundos, retirada sequencial dos recipientes após 5 minutos com defasagem de 5 segundos e medição do volume coletado. Foi utilizado o método gravimétrico para a determinação do volume coletado de cada emissor, expressando os valores de vazão em $\mathrm{L} \mathrm{h}^{-1}$, utilizando uma balança de precisão certificada. Os dados obtidos foram submetidos à análise de variância pelo teste $\mathrm{F}$ ao nível de 1 e $5 \%$ de probabilidade, e em casos de significância, foi realizada a análise de regressão e as médias foram comparadas entre si pelo teste Tukey à 5\% de probabilidade. O entupimento parcial foi mais severo na lâmina de $100 \%$ de reposição hídrica, sendo maior do que o da lâmina de 50\% em 58\% dos meses de avaliação.

Palavras-chave: Lâminas de irrigação, vazão, irrigação localizada, gotejamento enterrado.

\footnotetext{
${ }^{1}$ Doutorando em Ciências Agrárias - Agronomia, Instituto Federal Goiano - Campus Rio Verde, Rodovia Sul Goiana, Km 01, CEP: 75.901-170, Rio Verde-GO, e-mail: fernandonobrecunha@hotmail.com

2 Doutorando em Ciências Agrárias - Agronomia, IFGoiano - Campus Rio Verde, e-mail: nelmiciofurtado@gmail.com

${ }^{3}$ Eng. Agrônomo, Prof. Dr. em Agronomia, IFGoiano - Campus Rio Verde, e-mail: marconibt@gmail.com

4 Mestranda em Ciências Agrárias - Agronomia, IFGoiano - Campus Rio Verde, e-mail: lucianaminervina@gmail.com

${ }^{5}$ Graduando em Agronomia, IFGoiano - Campus Rio Verde, e-mail: fernandorcfilho@gmail.com

${ }^{6}$ Mestrando em Ciências Agrárias - Agronomia, Instituto Federal Goiano - Campus Rio Verde, Rodovia Sul Goiana, Km 01, CEP: 75.901-170, Rio Verde-GO, e-mail: flaviohenriquefg@hotmail.com
} 


\title{
CLOGGING DEGREE OF A SYSTEM OF SUBSURFACE DRIP IN CULTURE JATROPHA (Jatropha curcas L.)
}

\begin{abstract}
The use of trickle irrigation systems has been expanding increasingly due to its low water consumption and high rate of uniformity, however a common problem of drip irrigation emitters and clogging by solid particles compounded in subsurface irrigation systems. Thus, the objective was to evaluate the influence of the degree of clogging in different irrigation levels over time in the flow and uniformity of application of water in an irrigation system located subsurface. The procedure for individual reading of the flow of the drippers consisted of pressurization system, positioning containers (1 liter) under the respective drains of the buried emitter potted with a lag of 5 seconds sequential removal of containers 5 minutes after 5 second lag and measuring the collected volume. The gravimetric method was used for determining the volume collected from each emitter, expressing the flow values of $\mathrm{L} \mathrm{h}^{-1}$ using a certified precision balance. The data were submitted to analysis of variance by $\mathrm{F}$ test at 1 and $5 \%$ probability, and in cases of significance, regression analysis was performed and means were compared by Tukey test at $5 \%$ probability. The partial clogging was most severe in the blade $100 \%$ water replacement, and greater than $50 \%$ of the blade at $58 \%$ of the month evaluation.
\end{abstract}

Keywords: Water depth, flow, drip irrigation, drip buried.

\section{INTRODUÇÃO}

A utilização de sistemas de irrigação localizada tem se expandido cada vez mais, devido seu baixo consumo de água e alta taxa de uniformidade, porém ocorre um problema frequente: obstrução de emissores. A alteração na vazão tem como sua pior hipótese a obstrução dos emissores, isso se deve pelos pequenos orifícios de passagem da água nos mesmos, ocorrendo com maior contundência na irrigação por gotejamento subsuperficial (BARROS et al. 2009; BUSATO; SOARES, 2010), ocasionando perda da uniformidade do sistema e variação da eficiência da irrigação (BARROS et al. 2009).

Além do entupimento dos emissores, fatores como pressão de operação, alinhamento da linha lateral, manutenção do conjunto motobomba, variação da vazão dos emissores, também afetam a uniformidade (SOUZA et al., 2005; CUNHA et al., 2013). Mesmo uma pequena porcentagem de emissores entupidos pode resultar em grande redução na uniformidade de aplicação de água e, como consequência, danos às plantas (NAKAYAMA; BUCKS, 1981).
Assim, se faz necessário a avaliação e manutenção periódica do sistema de irrigação, para que não haja agravamento dessas variações ao longo da distribuição de água e prevenção do entupimento dos emissores (TEIXEIRA et al., 2008), sendo uma importante etapa para obtenção de informações como o da eficiência de uso da água, qualidade da água, obstrução de emissores, variação da lâmina aplicada, porém torna-se mais difícil esse acompanhamento, quando se trabalha em sistemas de irrigação subsuperficiais. Para Souza (2012) poucas são as informações científicas disponíveis sobre a suscetibilidade à intrusão radicular em gotejadores enterrados. Diante do exposto, objetivou-se avaliar a influência do grau de entupimento em diferentes lâminas de irrigação ao longo do tempo sob a vazão e uniformidade de aplicação de água em um sistema de irrigação localizada subsuperficial.

\section{MATERIAL E MÉTODOS}

O experimento foi desenvolvido em casa de vegetação instalada na área experimental do IFGoiano - Campus Rio Verde. A casa de 
PINHÃO-MANSO (Jatropha curcas L.)

vegetação possui cobertura de filme plástico de polietileno transparente de 150 micras e laterais fechadas, com tela tipo sombrite com 30\% de interceptação.

A cultura do pinhão manso utilizada para a condução do experimento foi condicionada em vasos. Foi utilizado delineamento inteiramente casualizado, com cinco repetições, sendo utilizado um modelo de tubo gotejador e duas lâminas de irrigação (50 e 100\% de reposição hídrica).

As plantas cresceram inicialmente em um viveiro de mudas (fase de produção de mudas), depois transplantadas para os vasos quando as mudas atingiram entre 13 e $15 \mathrm{~cm}$. A área sistematizada para o transplante das mudas foi mantida saturada por 2 a 3 dias antes da operação. As mudas de pinhão-manso foram acondicionadas em recipientes (vasos plásticos) com dimensões de 0,4 m (diâmetro) x 0,60 m (altura) preenchidos com pedra brita $\mathrm{n}^{\circ} 02(0,1 \mathrm{~m})$ e solo separadamente, compondo uma camada de solo de 0,50 m de profundidade. Para a separação entre a camada de pedra e de solo, foi utilizada manta bidin, evitando a perda de solo pelo dreno. O tubo gotejador foi posicionado enterrado a $0,20 \mathrm{~m}$ de profundidade.

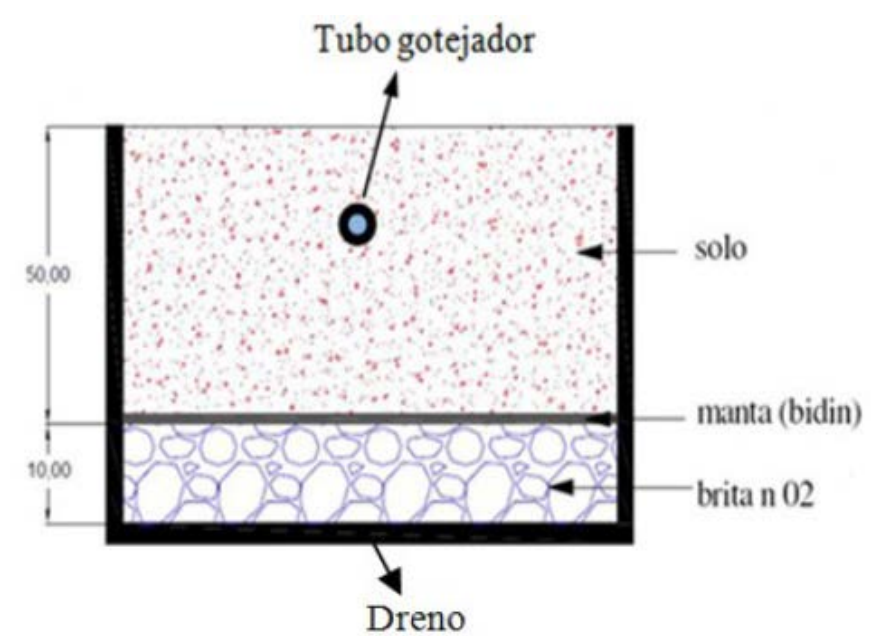

Figura 2. Esquema de montagem do recipiente para acondicionamento da cultura.

Antes do enchimento dos vasos, foi feita amostragem do solo utilizado como substrato em duas profundidades $(0-20 \mathrm{e}$ 20-40 cm) para análise física e química. $\mathrm{O}$ solo utilizado foi classificado como
Latossolo Vermelho distroférrico (LVdf), de textura média (EMBRAPA, 2006). As principais características químicas e físicas deste solo são apresentadas na Tabela 1.

Tabela 1. Características físico-químicas do Latossolo Vermelho distroférrico utilizado no preenchimento dos vasos, no início e no final do experimento.

\begin{tabular}{|c|c|c|c|c|c|c|c|c|c|c|}
\hline \multicolumn{11}{|c|}{ Análise Física } \\
\hline & Argila & & & & Silte & & \multicolumn{4}{|c|}{ Areia } \\
\hline & 410 & & & & 209 & & \multicolumn{4}{|c|}{381} \\
\hline \multicolumn{11}{|c|}{ Análise Química } \\
\hline $\mathrm{P}^{1}$ & M.O' & $\mathrm{pH}^{3}$ & $\mathrm{~K}^{1}$ & $\mathrm{Ca}$ & $\mathrm{Mg}$ & $\mathrm{H}+\mathrm{Al}$ & $\mathrm{S}^{4}$ & $\mathrm{~T}^{5}$ & $\mathrm{Al}$ & $\mathrm{V}^{6}$ \\
\hline $\mathrm{mg} / \mathrm{dm}^{3}$ & $\%^{3}$ & água & & -------- & ------ & $\mathrm{nmol} / \mathrm{dm}$ & ------- & -------- & & $\%$ \\
\hline 3,92 & 43,27 & 6,1 & 2,81 & 57,20 & 19,20 & 64,35 & 79,21 & 143,56 & 0,00 & 55,18 \\
\hline
\end{tabular}

${ }^{1}$ Extrator de P e K, Mehlich-1; ${ }^{2}$ M.O Matéria Orgânica; ${ }^{3} \mathrm{pH}$ em água, g/100 $\mathrm{cm}^{3}$ de terra. ${ }^{4} \mathrm{~S}$ Soma de bases, Ca + Mg + K. ${ }^{5}$ T Capacidade de troca de cátions, $\mathrm{S}+\mathrm{H}+\mathrm{Al} .{ }^{6} \mathrm{~V}$ Porcentagem de saturação de bases, V=100 S/T. 
Os tratamentos tiveram início após 30 dias de estabelecimento da cultura, sendo irrigadas nesse período com uma lâmina de reposição hídrica suficiente para manter o solo em sua capacidade de campo.

Foi utilizado o tubo gotejador Naan Drip (NAAN) de fluxo turbulento, com pressão de serviço recomendada pelo fabricante de 1,0 bar), e vazão de $1,5 \mathrm{~L} \mathrm{~h}^{-1}$. Foram posicionados um gotejador por vaso. Um hidrômetro foi instalado antes das entradas das linhas para determinação do consumo de água durante o desenvolvimento do experimento.

Para a medição da pressão de serviço, à entrada da linha de emissores foi utilizado um manômetro de bourdon digital com faixa de leitura de $0-4 \mathrm{Kgf} \mathrm{cm}^{-2}$, permitindo que a cada medição de vazão a pressão fosse checada e, se necessário, ajustada àquela preestabelecida.

O procedimento para leitura individual da vazão dos gotejadores consistiu da pressurização do sistema até que iniciasse e estabilizasse $o$ processo de drenagem no orifício inferior dos vasos, então, eram posicionados recipientes (1 litro) sob os respectivos drenos com uma defasagem de 5 segundos, retirada sequencial dos recipientes após 5 minutos com defasagem de 5 segundos e medição do volume coletado.

Para maior exatidão, foi utilizado o método gravimétrico para a determinação do volume coletado de cada emissor, expressando os valores de vazão em $\mathrm{L} \mathrm{h}^{-1}$, utilizando uma balança de precisão certificada. Foram avaliados mensalmente 10 gotejadores por tratamento, totalizando.

Posteriormente, os dados foram tabulados e feitos os cálculos da vazão, de uniformidade de distribuição de água, da vazão relativa e do grau de entupimento utilizando as equações enumeradas de 1 a 5 .

$$
q=\frac{P}{1000 t} 60
$$

$$
\begin{gathered}
Q_{r}=\frac{Q_{x, y}}{Q_{i}} \\
C U C=100\left\{1-\frac{\sum_{i=1}^{n}|X i-\bar{X}|}{n \cdot \bar{X}}\right\} \\
C U E=100\left(1-\frac{S}{\bar{X}}\right) \\
\mathrm{GE}=\left(1-\frac{\mathrm{q}_{\text {usado }}}{\mathrm{q}_{\text {novo }}}\right) 100
\end{gathered}
$$

em que:

$\mathrm{Q}_{\mathrm{r}}$ - vazão relativa, \%;

$\mathrm{Q}_{\mathrm{x}, \mathrm{y}}$ - vazão de um emissor $\mathrm{x}$ num dia $\mathrm{y}$ de irrigação, $\mathrm{L} \mathrm{h}^{-1} \mathrm{e}$

$\mathrm{Q}_{\mathrm{i}}$ - vazão desse emissor no primeiro dia de irrigação, $\mathrm{L} \mathrm{h}^{-1}$.

$P$ - peso da água coletada, g;

$t$ - tempo de coleta, min;

$q$ - vazão do gotejador, $\mathrm{L} \mathrm{h}^{-1}$;

GE - grau de entupimento, \%.

CUC - Coeficiente de uniformidade de Christiansen, em \%.

CUE - Coeficiente de uniformidade estatístico, em \%.

$\bar{X}$ - vazão média dos gotejadores, em $\mathrm{L} \mathrm{h}^{-1}$;

$X_{i}$ - vazão de cada gotejador, em $\mathrm{L} \mathrm{h}^{-1}$;

$n$ - número de gotejadores observados;

$s$ - desvio padrão da vazão dos gotejadores usados, $\mathrm{L} \mathrm{h}^{-1}$.

Os dados obtidos foram submetidos à análise de variância pelo teste $\mathrm{F}$ ao nível de $1 \mathrm{e}$ $5 \%$ de probabilidade, e em casos de significância, foi realizada a análise de regressão e as médias foram comparadas entre si pelo teste Tukey à 5\% de probabilidade.

adequou-se a uma equação linear decrescente para ambas as lâminas de irrigação (50 e 100\%), respectivamente, (Figuras 2A e B). 
A)

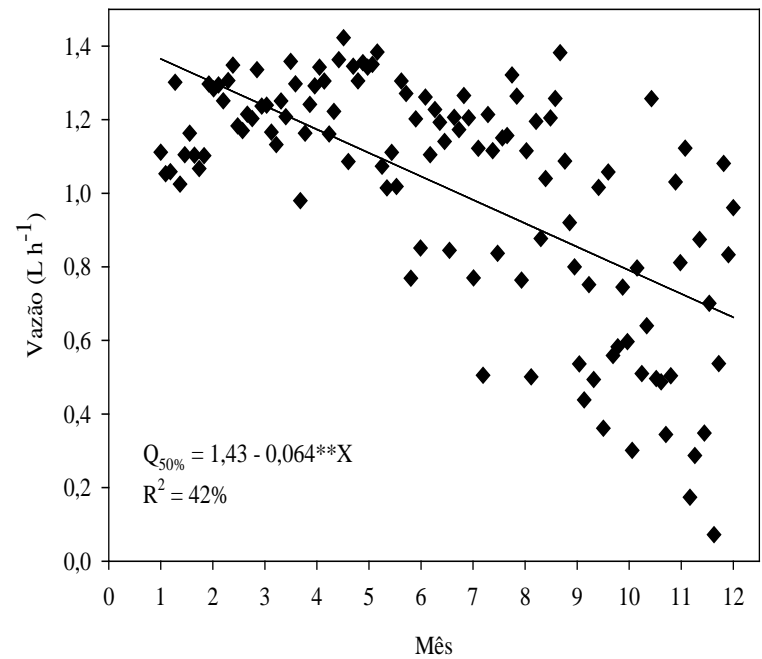

B)

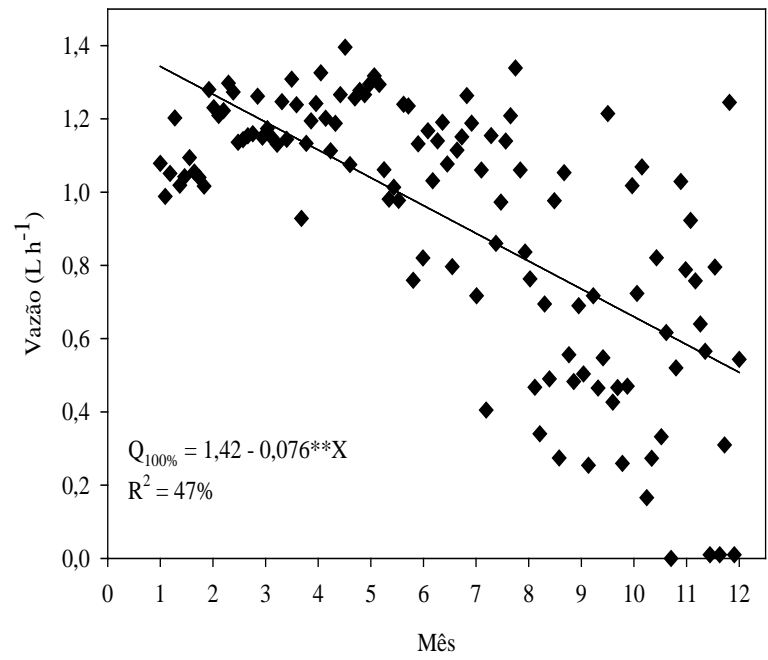

Figura 2. Vazão em função do mês de avaliação para a lâmina de 50\% (A) e 100\% (B).

Ocorreu uma tendência de queda na vazão conforme o tempo de avaliação foi se tornando maior, ocorrendo a diminuição da mesma para as duas lâminas de irrigação, porém havendo pontos contrastantes, como pode ser visto na Tabela 2, onde representa as médias da vazão para cada mês de avaliação em ambas as lâminas de irrigação. Os gotejadores apresentaram redução da vazão na condição subsuperficial do experimento desde a primeira avaliação no sistema. Para Mélo (2007) e Ribeiro et al., (2010) a quantificação da vazão em sistemas de irrigação e/ou do próprio emissor é um parâmetro de extrema confiança para determinação das alterações de forma a determinar o funcionamento, principalmente em função do entupimento dos emissores.

Tabela 2. Vazão e grau de entupimento com relação aos meses de avalição para a lâmina de 50 e $100 \%$.

\begin{tabular}{ccccccccc}
\hline \multirow{2}{*}{ Mês } & \multicolumn{4}{c}{ Vazão $\left(\mathrm{L} \mathrm{h}^{-1}\right)$} & \multicolumn{3}{c}{ Grau de entupimento (\%) } \\
\cline { 2 - 8 } & \multicolumn{2}{c}{$50 \%$} & $100 \%$ & \multicolumn{2}{c}{$50 \%$} & \multicolumn{2}{c}{$100 \%$} \\
\hline 1 & 1,05 & b & 1,29 & a & 20,61 & a & 20,67 & a \\
2 & 1,07 & a & 1,02 & a & 19,09 & b & 37,12 & a \\
3 & 1,21 & a & 1,12 & b & 8,48 & b & 31,17 & a \\
4 & 1,14 & a & 1,15 & a & 13,33 & b & 29,26 & a \\
5 & 1,10 & a & 1,14 & a & 16,51 & b & 29,94 & a \\
6 & 1,14 & a & 1,17 & a & 13,79 & b & 27,97 & a \\
7 & 1,04 & b & 1,25 & a & 21,36 & a & 23,56 & a \\
8 & 0,84 & a & 0,63 & b & 36,36 & b & 61,59 & a \\
9 & 0,62 & a & 0,71 & a & 53,03 & a & 56,56 & a \\
10 & 0,55 & b & 0,65 & a & 58,03 & a & 59,94 & a \\
11 & 0,67 & a & 0,44 & b & 49,24 & b & 72,88 & A \\
12 & 0,37 & a & 0,45 & a & 72,04 & a & 72,39 & A \\
\hline
\end{tabular}

*Médias seguidas de mesma letra nas linhas não diferem significativamente entre si segundo teste Tukey a 5\% de probabilidade.

Nota-se que na lâmina de $50 \%$ a partir do $2^{\circ}$ mês de avaliação a vazão tende a aumentar até o $6^{\circ}$ mês sendo maior que no mês inicial, onde a partir daí ela volta a diminuir atingindo seu menor valor de $0,37 \mathrm{~L}$ $\mathrm{h}^{-1}$ no mês 12, sendo o último mês de 
avaliação. Para a lâmina de $100 \%$ nota-se a mesma tendência, porém a partir do mês 3 até o mês 7, após esse período a vazão reduz, com ressalva para pequenas variações nesses meses seguintes, até atingir seu menor valor no mês 11 de $0,44 \mathrm{~L} \mathrm{~h}^{-1}$.

Comparando-se as médias das vazões entre as lâminas de irrigação, observa-se que apenas nos meses 1, 3, 7, 8, 10 e 11 as vazões diferiram-se estatisticamente, sendo que no mês 3, 8, e 11 a média da vazão da lâmina de $50 \%$ foi superior a de $100 \%$ de irrigação, com diferenças de 7,4, 25 e 34\%, respectivamente; já o inverso (lâmina de 100\% maior do que a de $50 \%$ ) ocorreu nos meses 1,7 e 10 , com diferenças de 18,6, 16,8 e 15,4\%, respectivamente. Nos demais meses as vazões foram estatisticamente iguais entre as lâminas de $50 \%$ e $100 \%$.

Analisando-se o mês 1 com o 12 de cada lâmina, nota-se que houve um decréscimo de 64,76 e 65,12\% na vazão das lâminas de 50 e 100\%, respectivamente. Essa discrepância nos valores de vazão nos meses subsequentes em relação a vazão nominal dos gotejadores, mostra-se mais evidente em sistemas de irrigação subsuperficial, que deve-se segundo Cunha et al. (2014) a sucção de partículas do solo via gotejador, promovendo o entupimento do mesmo.

Ainda na Tabela 2, encontram-se os valores da média do grau de entupimento (GE) dos emissores para as lâminas de 50 e 100\% conforme os meses de avaliação. Nota-se que, as médias do GE entre as lâminas de irrigação diferiram-se estatisticamente apenas nos meses $2,3,4,5,6,8$ e 11, sendo que em todos os casos, a lâmina de $50 \%$ apresentou as menores médias de grau de entupimento, com diferenças de 18, 22,7, 15,9, 13,4, 14,2, 25,2 e 23,6\%, respectivamente, já nos demais meses avaliados os valores são estatisticamente iguais entre as lâminas de irrigação.

Nota-se que há uma tendência clara nos valores de vazão e grau de entupimento para as duas lâminas de irrigação, onde o aumento e diminuição da vazão é inversamente proporcional ao aumento e diminuição do GE. Vale ressaltar que as pequenas variações que ocorrem na vazão ao longo dos meses não podem ser atribuídas apenas ao entupimento, pois tem-se as oscilações oriundas do manômetro utilizado e do sistema motobomba (SOUZA et al., 2012).

Conforme afirmam Dalri et al. (2014) a ausência de variações bruscas na vazão não caracteriza interferência e/ou ocorrência de entupimento nos emissores. Porém pode-se aferir que a diminuição da vazão deve-se ao entupimento dos emissores, conforme foi visto na tendência dos valores entre a vazão e o grau de entupimento na Tabela 2.

A uniformidade de aplicação do sistema foi determinada pelo Coeficiente de Uniformidade de Christiansen (CUC) e Coeficiente Estatístico de Uniformidade (CUE), adequando-se a análise de regressão a equações lineares decrescentes para ambas as lâminas de irrigação ao longo dos meses de avaliação (Figuras 3A e 3B). Da mesma forma que a vazão, de modo geral, a uniformidade de aplicação foi cada vez menor conforme o avanço dos meses de avaliação. 
A)

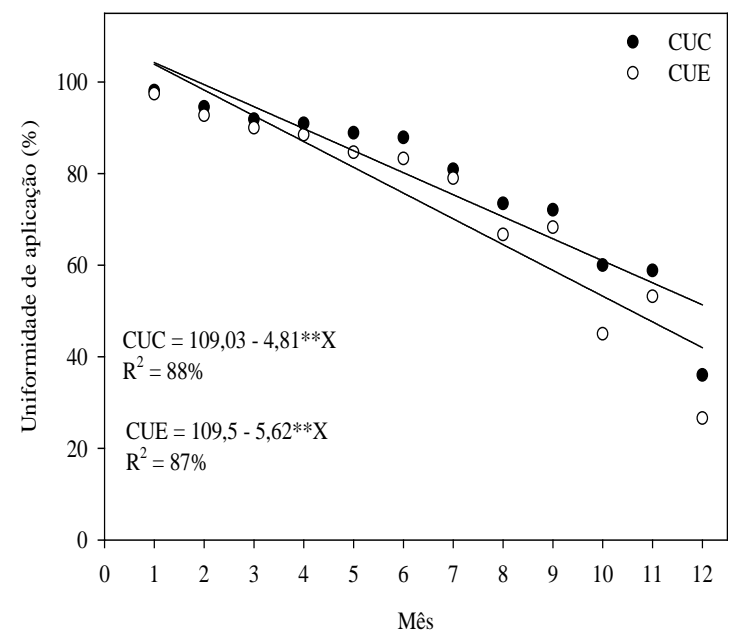

B)

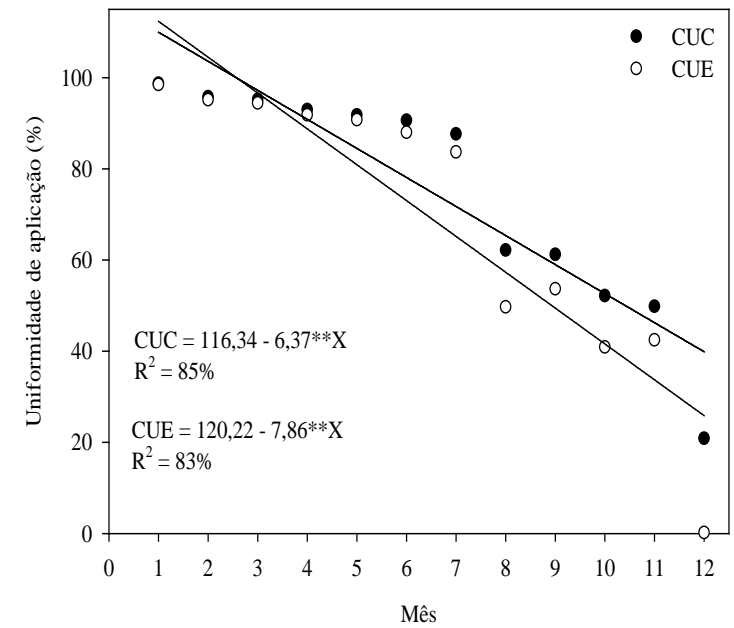

Figura 3. Uniformidade de aplicação de água em função do mês de avaliação para a lâmina de $50 \%$ (A) e $100 \%(B)$.

Segundo recomendação da ASAE (2003) para não prejudicar a uniformidade de aplicação de água do sistema de irrigação a variação máxima dos emissores deve ser de $10 \%$ em todo o sistema, sendo que o CUC é considerado excelente acima de $90 \%$ mesmo no sistema subsuperficial (MANTOVANI, 2001). Conforme Souza et al., (2005) esses valores devem se encontrar na faixa de $85 \%$ à 95\%, valores esses determinados em campo.

Portanto, nota-se pela Figura 3 que apenas até o $4^{\circ}$ e $6^{\circ}$ mês de avaliação o CUC do sistema se manteve excelente para as lâminas de 50 e $100 \%$ de irrigação, respectivamente. A medida que do $5^{\circ}$ ao $7^{\circ}$ mês o CUC se manteve bom para as lâminas de 50 e $100 \%$, respectivamente, também conforme a classificação de Mantovani et al., (2001). Após esses meses, por ser uma equação linear decrescente, a uniformidade foi classificada como regular (<80\%) no sistema de irrigação, para ambas as lâminas de irrigação.

Segundo Zocoler (2005), valores de CUC < 90\% são aceitos apenas quando a precipitação tem um valor significativo durante o período de cultivo em sistemas de irrigação localizada, o que portanto não ocorreu no presente estudo, não podendo justificar os valores menores que $90 \%$.

Nota-se então um bom desempenho do sistema instalado com base no CUC, até o $7^{\circ}$ mês de funcionamento do mesmo para ambas as lâminas de irrigação no presente estudo. Para o CUE, este se mantém acima de $80 \%$ até o mês 7 para as lâminas de 50 e 100\%, sendo classificado como bom para o sistema de irrigação localizada, após esse período seus valores ficaram abaixo de $80 \%$ não sendo portanto satisfatórios para esse tipo de sistema de irrigação.

Nota-se também que os valores de CUE são ligeiramente menores que o de CUC em ambas as lâminas de irrigação para todos os meses, isso ocorre devido CUE dá um tratamento mais rigoroso a problemas de distribuição de água, que ocorrem ao longo da linha lateral (RODRIGUES et al., 2013). A redução acentuada na uniformidade de aplicação de água deve-se principalmente aos elevados valores do GE.

Para a variável grau de entupimento, a regressão adequou-se a uma equação linear crescente, ou seja, para as duas lâminas de irrigação, conforme o avanço dos meses de avaliação, o grau de entupimento aumentou (Figura 4). Visto que, na tabela 1 pode-se observar que houve pequenas variações ao longo dos meses, interferindo diretamente nos valores de vazão (Figura 2 e 3) e uniformidade de aplicação (Figura 3). 


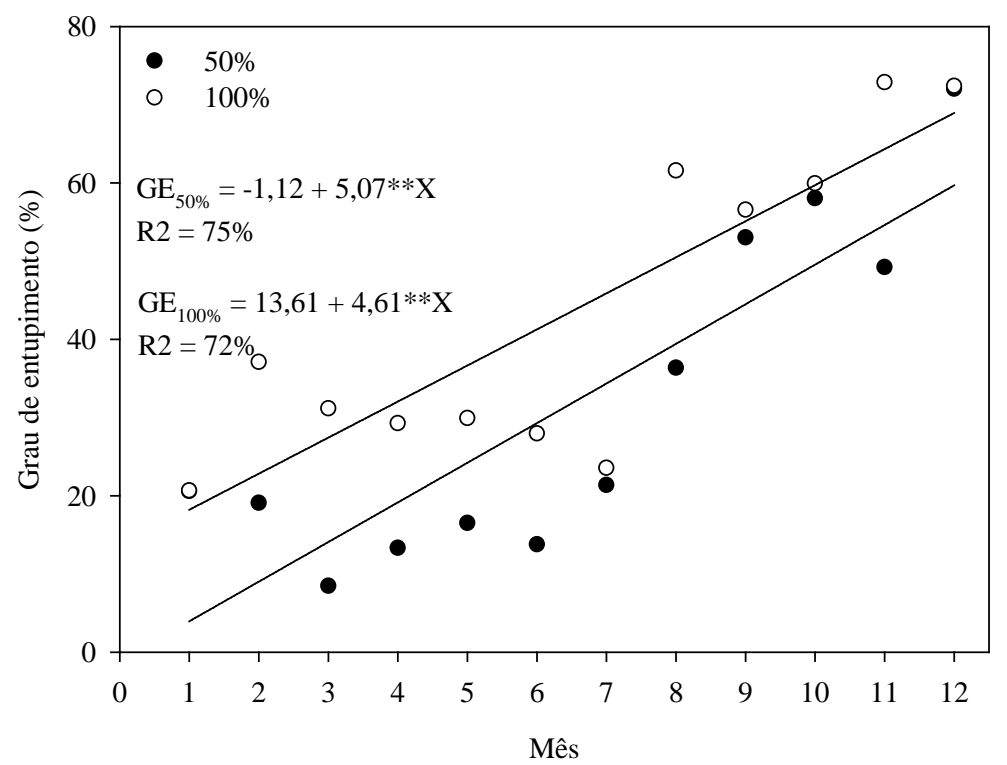

Figura 4. Grau de entupimento em função do mês de avaliação para a lâmina de 50 e 100\%.

Um dos principais problemas relacionados ao método de irrigação subsuperficial com fitas gotejadoras conforme afirmam Keller \& Bliesner (1990), devido ao pequeno diâmetro do orifício dos emissores é o entupimento dos mesmos por partículas solidas de solo, entre outros.

Nota-se a partir dos meses 8 e 9 o GE foi superior que $40 \%$ para as lâminas de 100 e $50 \%$ de irrigação, respectivamente. Segundo Dalri et al. (2014) o GE calculado inferior a $40 \%$ indica que não houve emissores entupidos, o que ocorreu portanto até o mês 7 de avaliação para ambas as lâminas de irrigação, após isso ocorreu entupimento dos emissores, e portanto os valores de vazão menores podem ser atribuídos e confirmam os altos valores de GE a partir desses meses de avaliação conforme as Figuras 2.

A redução na vazão é ocorrência de outro problema comumente enfrentado nesse tipo de sistema de irrigação, o entupimento parcial dos emissores, que tem por agravamento de não ser perceptível a analise visual, como é possível no entupimento total.

Nota-se que para todos os meses e para todas as lâminas de irrigação, a vazão relativa foi sempre menor do que aquela determinada na avaliação inicial do sistema (vazão nominal dos emissores). Sendo que nos meses 1, 2, 4, 6, 7 e 9 a vazão relativa da lâmina de $50 \%$ foi superior que a de 100\%, (Figura 5).

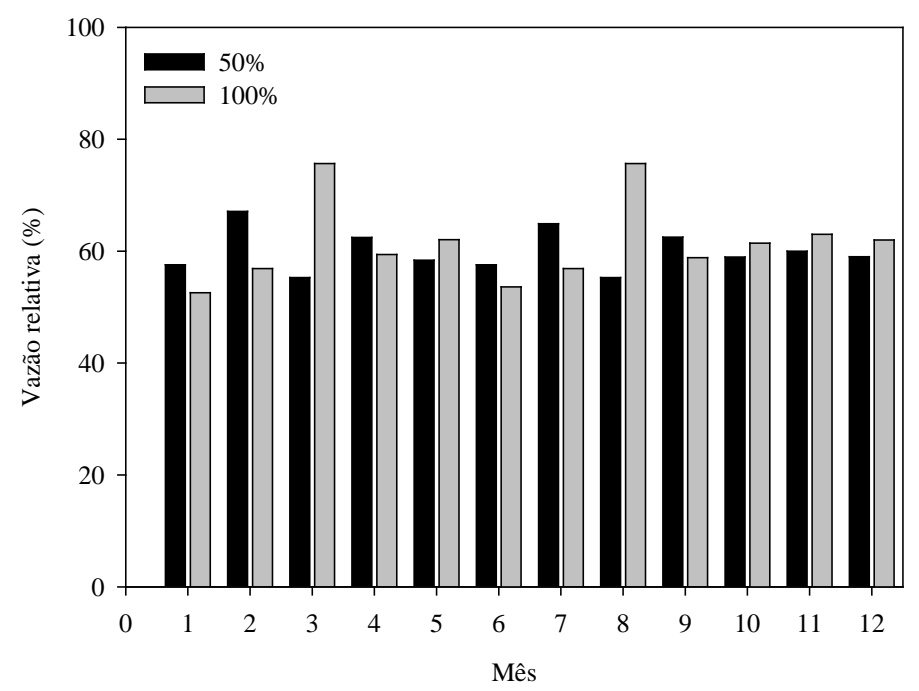

Figura 5. Vazão relativa em função do mês de avaliação para a lâmina de 50 e 100\%. 
De acordo com a Figura 5 não foi observado um valor inferior a $50 \%$, ou seja, a vazão não chegou a ser reduzida pela metade em nenhum dos casos. Sendo que o menor valor ocorreu no mês 1, na lâmina de $100 \%$. Essa redução na vazão relativa deve-se ao entupimento parcial dos emissores.

\section{CONCLUSÃO}

A vazão para a lamina de 50 e $100 \%$ diferiram em $25 \%$ dos meses com diferenças máximas de 34,3 e 18,6\%, respectivamente.

O entupimento parcial foi mais severo na lâmina de $100 \%$, sendo maior do que o da lâmina de $50 \%$ em $58 \%$ dos meses de avaliação.

A uniformidade se manteve excelente para as lâminas de 50 e $100 \%$ de irrigação até no sexto mês de avaliação.

O sistema radicular do pinhão manso por ser bastante agressivo, teve impacto preponderante na redução da vazão e consequente equiparação no entupimento parcial entre as lâminas no último mês de avaliação.

\section{REFERÊNCIAS BIBLIOGRÁFICAS}

ASAE - American Society of Agricultural Engineers.ASAE EP 405.Design and installation of microirrigation systems.In: ASAE Standsrds 2003. St. Joseph: ASAE. 2003. p.900-905.

BARROS, A. C.; COELHO, R. D.; MEDEIROS, P. R. F.; MELO, R. F.; BARBOZA JUNIOR, C. R. A.; DIAS, C. T. S. Entupimento de gotejadores em função da aplicação de superfosfato simples e ácido nítrico. Revista Engenharia Agrícola, Jaboticabal, v.29, n.1, p.62-71, 2009;

BUSATO, C. C. M.; SOARES. A. A. Desempenho de gotejadores, utilizando água de baixa qualidade química e biológica.
Bioscience Journal, Uberlândia, v.26, n.5, p.739-746, 2010;

CUNHA, F. N.; OLIVEIRA, R. C.; SILVA, N. F.; MOURA, L. M. F.; TEIXEIRA, M. B.; GOMES FILHO, R. R. Variabilidade temporal da uniformidade de distribuição em sistema de gotejamento. Revista Brasileira de Agricultura Irrigada, v.7, n.4, p.248-257, 2013;

CUNHA, F. N.; SILVA, N, F.; TEIXEIRA, M. B.; CARVALHO, J. J.; MOURA, L. M. F.; SANTOS, C. C. Coeficientes de uniformidade em sistema de irrigação por gotejamento. Revista Brasileira de Agricultura Irrigada, v.8, n.6, p.444-454, 2014;

DALRI, A. B.; PALARETTI, L. F.; CRUZ, F. L.; ZANINI, J. R.; FARIA, R. T.; SANTOS, G. O. Entupimento de emissores enterrados sob a cultura da cana-de-açúcar após três anos de cultivo em condições fertirrigadas. Irriga, Botucatu-SP, Edição especial 1, p.62-71, 2014;

KELLER, J.; BLIESNER, I.D.Sprinkler and trickle irrigation. New York: Van Nostrand Reinhold, 1990. 652p;

MANTOVAni, E. C. Avalia: Programa de Avaliação da Irrigação por Aspersão e Localizada. Viçosa, MG: UFV, 2001;

MÉLO, R. F. Dinâmica e controle do entupimento de gotejadores em função de precipitados químicos e plâncton. Tese (Doutorado em Irrigação e Drenagem) Escola Superior de Agricultura "Luiz de Queiroz”, Universidade de São Paulo, Piracicaba, 2007, 189p;

NAKAYAMA, F. S.; BUCKS, D. A. Emitter clogging effects on trickle irrigation uniformity. Transactions of the ASAE, St. Joseph, v.24, n.4, p.77-80, 1981.

RIBEIRO, P. A. de A.; COELHO, R. D.; TEIXEIRA, M. B. Entupimento de tubos 
gotejadores convencionais com aplicação de cloreto de potássio (branco e vermelho) via duas qualidade de água. Revista Engenharia Agrícola, Jaboticabal, v.30, n.2, p.279-287, mar./abr. 2010;

RODRIGUES, R. R.; COLA, M. P. A.; NAZÁRIO, A. A.; AZEVEDO, J. M. G.; REIS, E. F. Eficiência e uniformidade de um sistema de irrigação por gotejamento na cultura do cafeeiro. Ambiência Guarapuava, v.9, v.2, p.323-334, 2013.

SILVA, C. A.; SILVA, C. J. Avaliação de uniformidade em sistemas de irrigação localizada. Publicação Científica da Faculdade de Agronomia e Engenharia Florestal, n.8, dezembro, 2005;

SOUZA, I. H.; ANDRADE, E. M.; SILVA, E. L. Avaliação hidráulica de um sistema de irrigação localizada de baixa pressão, projetado pelo software "bubbler". Revista Engenharia Agrícola, Jaboticabal, v.25, n.1, p.264-271, 2005;

SOUZA, W. de J. Protótipos e avaliação de emissores para irrigação localizada subsuperficial. 110p. 2012. Tese (Doutorado)
- Escola superior de agricultura "Luiz de Queiroz”, 2012.

SOUZA, W. J.; BOTREL, T. A.; COELHO, R. D.; NOVA, N. A. V. Irrigação localizada subsuperficial: Gotejador convencional e novo protótipo. Revista Brasileira de Engenharia Agrícola e Ambiental, Campina Grande-PB, v.16, n.8, p.811-819, 2012;

TEIXEIRA, M. B.; MELO, R. F. de; COELHO, R. D.; RETTORE NETO, O.; RIBEIRO, P. A. de A. Tratamento para desentupimento de gotejadores convencionais. Brazilian Journal of Irrigation and Drainage - IRRIGA, Botucatu, v.13, n.2, p.235-248, 2008;

WERNECK, J.E. F.; Ferreira, R.S.A. \& CHRISTOFODIS, D. O uso da água para irrigação. 2009. Disponível em: $<$ http://www.cf.org.br/cf2004/irrigacao.doc >. Acesso em: 20 fev. 2012;

ZOCOLER, J. L. Avaliação de desempenho de sistemas de irrigação. Ilha Solteira - SP: UNESP. Disponível em $<$ http://www.agr.feis.unesp.br/irrigacao.html> . Acesso em 27 jun. 2005. 